\title{
Fenologia Vegetativa e Crescimento de Cedrela fissilis na Floresta Atlântica, Paraná, Brasil
}

\author{
Fernando Andreacci ${ }^{1}$, Paulo Cesar Botosso ${ }^{2}$, Franklin Galvão ${ }^{3}$ \\ ${ }^{1}$ Universidade do Vale do Itajaí - UNIVALI, Itajaí/SC, Brasil \\ ${ }^{2}$ Empresa Brasileira de Pesquisa Agropecuária - EMBRAPA, Colombo/PR, Brasil \\ ${ }^{3}$ Universidade Federal do Paraná - UFPR, Curitiba/PR, Brasil
}

\begin{abstract}
RESUMO
A fenologia, o incremento em circunferência do tronco e a atividade cambial de indivíduos de Cedrela fissilis (Meliaceae) foram observados mensalmente em duas tipologias de Floresta Ombrófila (Densa e Mista) na Floresta Atlântica, Estado do Paraná, Brasil. As observações se deram por meio do método de índice de atividade, leitura de incremento em circunferência do tronco com o uso de dendrômetros permanentes e amostragens periódicas de tecido cambial de 24 árvores da espécie. O ritmo de incremento observado é sazonal, iniciando-se após a expansão total do limbo e interrompendo-se quando as folhas maduras estão em senescência adiantada e/ou em sua ausência. Análises estatísticas mostraram relações significativas entre incremento, variáveis climáticas e fenologia. A espécie apresenta formação de anéis anuais de crescimento, sendo observadas flutuações anatômicas intra-anuais. Os resultados indicam que a fenologia vegetativa dos indivíduos parece ser influenciada mais fortemente pelo fotoperíodo e temperatura do que pela precipitação.
\end{abstract}

Palavras-chave: floresta ombrófila, dendrômetros, atividade cambial.

\section{Vegetative Phenology and Growth of Cedrela fissilis in Atlantic Forest, Southern Brazil}

\begin{abstract}
Phenology, girth trunk increment and cambial activity of Cedrela fissilis (Meliaceae) individuals were monthly evaluated in two distinct units of the Atlantic Forest (Ombrophilous Dense and Mixed forests), in the state of Paraná, Brazil. Readings of 24 individuals were assessed by activity index, permanent band dendrometers, and periodic samplings of cambial tissue. The girth increment rhythm is seasonal, it begins after total leaf blade expansion and is suspended when mature leaves are in advanced senescence and/or absent. Statistical analysis shows significant relationships between girth increment, climatic variables and phenology. The species presents annual growth rings and intra-annual anatomical fluctuations. Its vegetative phenology seems to be more strongly driven by day length and temperature than by precipitation.
\end{abstract}

Keywords: ombrophilous forest, dendrometers, cambial activity. 


\section{INTRODUÇÃO}

A Floresta Atlântica, bioma brasileiro considerado um dos hotspots de excepcional biodiversidade e endemismo no mundo (Mittermeier et al., 2005), está distribuída ao longo da costa brasileira, apresentando amplitude latitudinal superior a 27 graus, com grandes variações altitudinais. Em toda sua extensão, esse bioma exibe diversificadas fitofisionomias propiciadas por uma variedade de ecossistemas interligados, cada qual com suas peculiaridades, as quais acompanham as características climáticas regionais (Rizzini, 1979).

No Sul do Brasil, particularmente no Estado do Paraná, esse bioma apresenta fitogeografia bastante diversificada, caracterizada por um nítido gradiente de tipos de ecossistemas relacionados ao mesoclima. Na planície costeira, encostas da Serra do Mar e em parte do planalto encontra-se a Floresta Ombrófila Densa, floresta perene adaptada às condições de temperatura elevada e precipitação abundante e regular. Nas áreas de maior altitude, principalmente nas regiões oriental e central do planalto, ocorre a Floresta Ombrófila Mista, caracterizada por elementos austral-antárticos adaptados à baixa temperatura e precipitação abundante e regular. Essa gama de situações climáticas e ecológicas cria uma enorme variação espacial e temporal na distribuição de recursos e de condições essenciais ao crescimento das plantas, influenciando diretamente nos processos fisiológicos das árvores.

Estudos fenológicos em regiões tropicais e subtropicais têm contribuído de forma expressiva para o entendimento das estratégias de crescimento de espécies arbóreas, possibilitando avaliar alterações no ritmo da atividade cambial dos indivíduos (Jacoby, 1989). Estudos conduzidos por Jacoby (1989) e Roig (2000) demonstram nítidas relações entre fenofases e variáveis climáticas e com a atividade cambial de espécies tropicais. Árvores tropicais mostram uma tendência de padrões fenológicos temporais relacionados com estações secas bem definidas, geralmente apresentando meses com precipitação inferior a $60 \mathrm{~mm}$ (Morellato et al., 1989; Van Schaik et al., 1993). Essa tendência pode estar, também, relacionada ao fato de que estudos fenológicos em regiões neotropicais têm sido conduzidos, em geral, em florestas estacionais, as quais apresentam variação anual na precipitação e temperatura. Entretanto, Hilty (1980) observou sazonalidades fenológicas em área de clima pouco sazonal, sugerindo que outros fatores climáticos são importantes na determinação dos ritmos fenológicos de regiões tropicais. Wright \& van Schaik (1994) apresentaram algumas evidências de que a luz é um importante fator regulador da fenologia de plantas tropicais, considerando o fotoperíodo fator responsável pelo comportamento sazonal da fenologia de algumas plantas frente ao clima pouco sazonal da região. Na Floresta Atlântica, Morellato et al. (2000) encontraram correlações positivas entre fenologia, fotoperíodo e crescimento radial em áreas de baixa sazonalidade climática no Sudeste do Brasil. Também em áreas da Floresta Atlântica no litoral paranaense, Cardoso et al. (2012) constataram correlações entre o comprimento do dia e a temperatura com a fenologia das espécies. Os autores apontam, também, que as características do solo podem alterar os processos fenológicos das espécies e, consequentemente, o seu crescimento. Já Callado et al. (2001) correlacionaram a periodicidade de crescimento radial das espécies com fenologia, temperatura, precipitação, fotoperíodo, regime de inundação e ritmos endógenos.

Apesar de fragmentados, os estudos sobre fenologia e incremento em circunferência de espécies tropicais e subtropicais, mais especificamente do domínio da Floresta Atlântica, têm demonstrado a alta complexidade de estratégias desenvolvidas pelas plantas desse ambiente.

O presente estudo avaliou a fenologia vegetativa e de crescimento em circunferência do tronco de 24 indivíduos adultos de Cedrela fissilis Vell. em duas condições ambientais distintas de Floresta Ombrófila, Densa e Mista, no Estado do Paraná, Brasil, procurando correlacionar os eventos com fatores climáticos e verificar a formação do anel de crescimento dessa espécie nas diferentes fitofisionomias. Objetivamos responder as seguintes questões: (i) A fenologia vegetativa da espécie é sincrônica entre as diferentes áreas? (ii) A fenologia e o crescimento em circunferência correlacionam-se com as variáveis ambientais? Os anéis de crescimento da espécie são formados anualmente?

\section{MATERIAL E MÉTODOS}

Foram avaliadas 24 árvores da espécie Cedrela fissilis, sendo que 7 indivíduos (DAP médio 19,9 \pm 14,8 cm) ocorriam naturalmente em área de Floresta Ombrófila Densa Submontana (FODSM) e 17 (DAP médio 
33,9 \pm 16,9 cm), em áreas de Floresta Ombrófila Mista Montana (FOMM) do Estado do Paraná, Brasil (Figura 1). Procurou-se selecionar indivíduos representativos da espécie nessas distintas formações vegetacionais e, aparentemente, em boas condições fitossanitárias e de formação do tronco e copa. Os indivíduos pertencentes à FODSM (área referida como "litoral") localizavam-se em área da Reserva Natural do Rio Cachoeira (2519'15”S; $45^{\circ} 42^{\prime} 24^{\prime \prime} \mathrm{W}$; área: 8.600 ha) pertencente à SPVS (Sociedade de Pesquisa em Vida Selvagem e Educação Ambiental), no município de Antonina, Paraná (Figura 1). Essa reserva é parte da Área de Proteção Ambiental de Guaraqueçaba, vasta região com mais de $300 \mathrm{mil}$ ha, uma das áreas remanescentes mais importantes da Floresta Atlântica no Brasil (Ferretti \& Britez, 2006). As árvores selecionadas encontravam-se em áreas florestais remanescentes sem indícios e/ou histórico de ação antrópica recente, em parcela experimental permanente a $300 \mathrm{~m}$ a.n.m. O clima da região é do tipo subtropical úmido mesotérmico (Cfa, segundo Köeppen), sem estação seca definida e com precipitações bem distribuídas ao longo do ano. Dados climáticos históricos (Figura 2) para um período de 33 anos (SIMEPAR, 2016) mostram médias anuais de precipitação e de temperatura de $2.565 \mathrm{~mm}$ e $21,3^{\circ} \mathrm{C}$ e $1.434 \mathrm{~mm}$ e $18,4{ }^{\circ} \mathrm{C}$ para as regiões de Antonina e Curitiba, respectivamente.
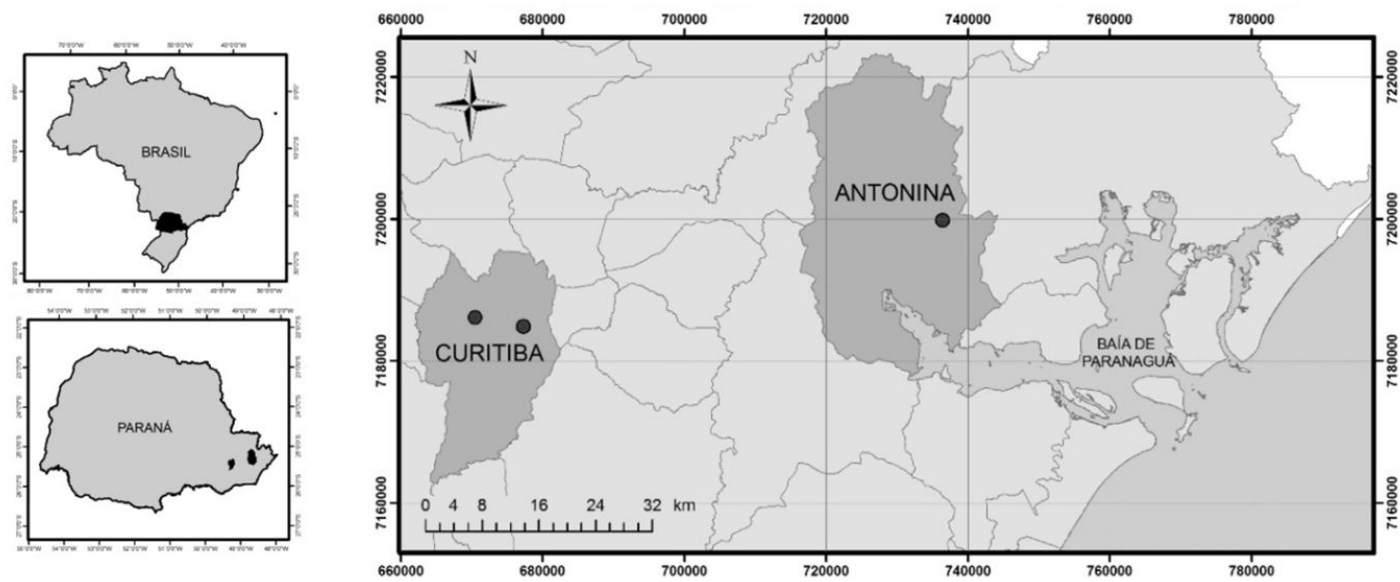

Figura 1. Localização das áreas de estudo nos municípios de Curitiba (Copel, Jardim Botânico) e Antonina (SPVS), Paraná, Brasil.

Figure 1. Location of the studied sites in Curitiba (C, J) and Antonina (S) municipalities, Paraná state, Brazil.
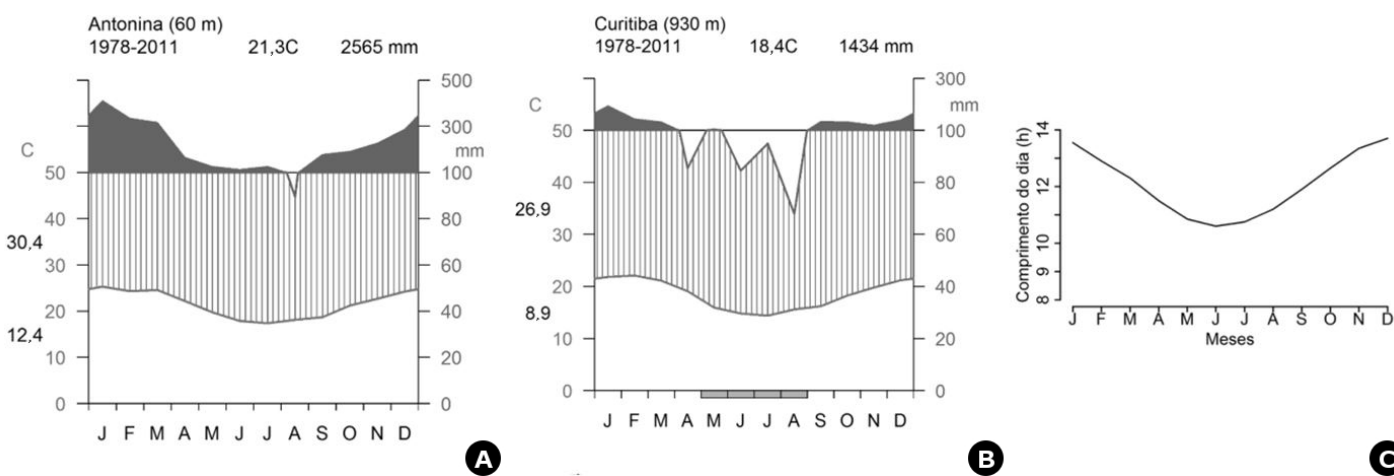

Figura 2. Diagramas climáticos para as regiões de Antonina (A) e Curitiba (B) (período: 1978-2011), elaborados segundo Walter \& Lieth (1967); (C) Comprimento do dia para a latitude de 25ㅇ. Fonte: Varejão-Silva (2000); Dados climáticos históricos - Sistema Meteorológico do Paraná - SIMEPAR (2016).

Figure 2. Climate diagrams for the regions of Antonina and Curitiba (period: 1978-2011), elaborated from Walter \& Lieth (1967); (C) Day length for $25^{\circ}$ S latitude. Source: Varejão-Silva (2000); Climatic data - SIMEPAR (2016). 
Os 17 indivíduos selecionados pertencentes à FOMM (áreas tratadas como "planalto") localizavam-se em duas áreas remanescentes de Floresta de Araucária atualmente protegidas e com vegetação secundária em estágio avançado de regeneração localizadas no perímetro urbano da cidade de Curitiba, Paraná, a altitude média de $945 \mathrm{~m}$ a.n.m. (Figura 1). Uma destas áreas, denominada Bosque do Bigorrilho (2525'56"S; $\left.49^{\circ} 18^{\prime} 16^{\prime} \mathrm{W}\right)$, pertencia à Companhia Paranaense de Energia (Copel), que a protege desde 1976. Nessa área de estudo foram selecionados 9 indivíduos adultos. A segunda área, o Bosque de Preservação Permanente do Jardim Botânico Municipal de Curitiba (2526’33"S; $\left.49^{\circ} 14^{\prime} 12^{\prime} \mathrm{W}\right)$, administrado pela Secretaria Municipal do Meio Ambiente desse município, compreende área que engloba mais de $40 \%$ (aproximadamente 7 ha) da área total do Jardim Botânico, com a entrada de pedestres restrita desde 2006. Nessa área, foram selecionados 8 indivíduos da espécie. O clima da região metropolitana de Curitiba é subtropical úmido mesotérmico de verões frescos, inverno com geadas frequentes e sem estação seca (tipo Cfb, segundo Köeppen). Para a faixa latitudinal das áreas de estudo, as diferenças no comprimento do dia podem atingir cerca de 3 horas ao longo do ano (Figura 2C).

Observações fenológicas das árvores foram realizadas mensalmente através do método de índice de atividade, levando-se em consideração as fenofases vegetativas: (i) brotamento; (ii) folhas maduras; (iii) folhas em senescência; e (iv) desfolha total. Esse método leva em consideração somente a presença ou ausência da fenofase no indivíduo, indicando a porcentagem de indivíduos da população que está manifestando determinado evento fenológico, não estimando a sua intensidade ou quantidade (Bencke \& Morellato, 2002). A sincronia dos eventos fenológicos foi estimada utilizando-se o índice de sincronia da população $(Z)$ proposto por Augspurger (1983). Foram concomitantemente realizadas leituras mensais de incremento em circunferência dos troncos com uso de dendrômetros, empregando-se o método considerado "dinâmico" (Fahn et al., 1981). O incremento em circunferência do tronco dos indivíduos selecionados foi avaliado por um período de 13 meses (de outubro de 2010 a novembro de 2011), com uso de faixas dendrométricas permanentes de aço inoxidável com 0,2 $\mathrm{mm}$ de precisão na leitura, instaladas à altura do peito (DAP 1,30 m do nível do solo) (Botosso \& Tomazello-Filho, 2001; Shimamoto et al., 2016). Dois meses após a instalação dos dendrômetros foi realizado o seu ajuste junto ao caule das árvores, de maneira a minimizar eventuais erros de medida. Os primeiros registros ocorreram três meses após essa instalação.

Paralelamente ao acompanhamento do incremento em circunferência do tronco e visando reconhecer os períodos de atividade e/ou de cessação de crescimento foram coletadas bimensalmente amostras de madeira contendo porções do floema, câmbio vascular e xilema secundário em dois indivíduos de cada formação florestal. As amostras foram fixadas em FAA, desidratadas em série etílica, incluídas em historesina (LEICA Historesin) e seccionadas em micrótomo rotativo. Os cortes foram corados com azul de toluidina (O’Brien, 1964) e observados sob microscopia óptica.

Com o objetivo de verificar e resumir o padrão de intercorrelações entre variáveis climáticas (temperatura, precipitação total e comprimento do dia), de um lado, e taxa média de crescimento e estado fenológico dos indivíduos, do outro, foi realizada uma análise fatorial exploratória denominada análise fatorial de dados mistos (Pagès, 2014). Essa análise é um método multivariado que pode ser visto como uma união entre uma análise de componentes principais e uma análise de correspondência múltipla.

\section{RESULTADOS E DISCUSSÃO}

A Tabela 1 apresenta o resultado do índice de sincronia (Z) para as duas regiões (litoral e planalto) e, para efeito de discussão, foi considerada uma abordagem comparativa englobando tanto os indivíduos do planalto como do litoral.

Cedrela fissilis apresentou comportamento anual decíduo, altamente sincrônico entre indivíduos de uma mesma área para todas as fenofases avaliadas. O sincronismo entre áreas foi regular para as fenofases

Tabela 1. Índice de sincronia das populações (Z). (i) brotamento; (ii) folhas maduras; (iii) senescência; (iv) desfolha total.

Table 1. Population index of synchrony (Z). (i) flushing; (ii) mature leaves; (iii) senescence; (iv) total leafless.

\begin{tabular}{lcccc}
\multirow{2}{*}{\multicolumn{1}{c}{ Área de estudo }} & \multicolumn{4}{c}{ Fenofases vegetativas } \\
\cline { 2 - 5 } & i & ii & iii & iv \\
\hline Planalto $(\mathrm{n}=17)$ & 0,96 & 0,95 & 0,96 & 0,93 \\
\hline Litoral $(\mathrm{n}=7)$ & 0,96 & 0,87 & 0,67 & 0,93 \\
\hline Planalto vs. litoral $(\mathrm{n}=7)$ & 0,96 & 0,77 & 0,59 & 0,62 \\
\hline
\end{tabular}


senescência e desfolha total, enquanto que brotamento e presença de folhas maduras foram altamente sincrônicos entre as áreas.

No início das observações fenológicas, em outubro de 2010, tanto no planalto quanto no litoral, os indivíduos expressavam duas fenofases distintas de forma sincrônica, brotamento (i) e folhas maduras (ii). Em novembro de 2010, todas as folhas já se apresentavam com a expansão total do limbo (ii), sendo que o brotamento já não era mais observado nesse mês. A fenofase folhas maduras estendeu-se até os meses de abril e maio, para as áreas planalto e litoral, respectivamente. No planalto, o amarelecimento dos folíolos, indicando a senescência foliar, pôde ser observado a partir do mês de fevereiro, enquanto que no litoral o amarelecimento é observado somente em abril. Essa antecipação na fase de senescência das folhas de $C$. fissilis observada no planalto pode ser atribuída, principalmente, aos verões predominantemente mais brandos, com temperaturas menores do que as registradas na área do litoral. Nos meses seguintes, ao primeiro sinal de senescência foliar, os indivíduos exibiram uma perda foliar gradual e progressiva, sendo que a desfolha total (iii) dos indivíduos ocorreu nos meses de junho e julho para ambas as áreas. Em geral, os indivíduos permaneceram sem folhas por um período de três meses no planalto (de junho a agosto) e por dois meses no litoral (de julho a agosto). A maximização da captura de luz pode dos fatores mais importantes a influir na fenologia de florestas tropicais (Van Schaik et al., 1993; Wright \& van Schaik, 1994). O’Brien et al. (2008) levantaram a hipótese de que a desfolha total dos indivíduos em meses de menor fotoperíodo minimizaria o impacto de fotossíntese reduzida por uma copa parcialmente sem folhas. Isso também maximizaria a quantidade de tempo para o desenvolvimento de folhas novas e dos cloroplastos anteriormente às melhores condições de luminosidade. Essa hipótese é inconsistente para o trabalho de O'Brien et al. (2008), tendo em vista que a desfolha acontece em meses com mais horas de luminosidade. Sendo assim, os autores levantaram outra hipótese, de que a desfolha de espécies decíduas poderia ser resposta aos meses mais secos, mesmo que não caracterizem uma estação seca bem definida. Entretanto, neste estudo, os meses que apresentaram fotoperíodos menores coincidiram com aqueles de desfolha dos indivíduos e, também, com os de menor precipitação (de junho a agosto), corroborando a primeira hipótese de O’Brien et al. (2008).

O início do brotamento em setembro de 2011 foi observado de forma sincrônica entre as áreas e estendeu-se até o mês de outubro. Diferentemente do observado nesse estudo, Lobão (2011) encontrou variações interanuais na fenologia de C. fissilis e C. odorata na Região Amazônica, sendo que o brotamento ocorreu em alguns anos por mais de 5 meses, provavelmente devido à baixa sincronia dos indivíduos. Para esse autor, a temperatura e a precipitação influenciaram o comportamento fenológico dos indivíduos estudados, inclusive o brotamento de novas folhas. O evento da brotação concentrou-se na transição dos meses de menor precipitação para aqueles com maior índice de precipitação e esse comportamento tem sido observado para Cedrela fissilis e outras espécies do gênero por diversos autores (Reich \& Borchert, 1984; Pinheiro et al., 1990; Marcati et al., 2006; Ferraz et al., 1999; Lobão, 2011). Esse comportamento é característico de algumas espécies de regiões com sazonalidade marcada por estação seca bem definida, nas quais a reidratação dos indivíduos causa o início do brotamento. Entretanto, em áreas com pouca sazonalidade e sem estação seca pronunciada, como no caso deste estudo, o brotamento das folhas dos indivíduos de C. fissilis assemelha-se ao ocorrido em áreas em que a precipitação é considerada fator limitante. Nos estudos de Ferraz et al. (1999) e Reich \& Borchert (1984), em áreas sem estação seca pronunciada, indivíduos do gênero Cedrela também apresentaram brotação sincrônica e regular. Espécies tropicais demonstram sazonalidade fenológica e esse comportamento tem sido atribuído principalmente à alternância entre períodos secos e chuvosos (Opler et al., 1976; Wright, 1991). Contudo, a sazonalidade da fenologia de $C$. fissilis observada neste estudo parece ser influenciada mais fortemente por outros fatores, já que há um suprimento hídrico praticamente constante em ambas as áreas. Alvim (1964), Rivera \& Borchert (2001) e Marques et al. (2004) demonstraram que padrões fenológicos em regiões mais afastadas do equador são mais fortemente influenciados por fotoperíodo e temperatura do que pela precipitação. Borchert (2000) apontou que o brotamento anual e sincrônico de uma espécie em uma paisagem pode ser ocasionado por mudanças no fotoperíodo, já que variações microambientais, como a disponibilidade de 
água, causariam alternância no ritmo de brotamento dos indivíduos.

Os dados observados mostraram que C. fissilis apresenta um comportamento decíduo, típico de espécies que vivem em ambientes com deficiência hídrica em pelo menos um período do ano. Essa sazonalidade fenológica, além de características morfológicas, indicam que a espécie mantém o comportamento típico de uma espécie com história evolutiva em um ambiente seco (Muellner et al., 2010). Contudo, o gatilho responsável pela indução da desfolha em C. fissilis nos ambientes estudados parece ser a diminuição do fotoperíodo, já que estão sob a influência de diferentes regimes de temperatura e sem estação seca pronunciada, porém em uma mesma latitude.
Pode-se inferir que a fenologia de C. fissilis é determinada geneticamente, variando coespecificamente entre os ecotipos adaptatos a diferentes latitudes, e deve ser controlada por diferentes sinais ambientais. Fotoperíodo e temperatura parecem influenciar diretamente a fenologia dos indivíduos, sendo o primeiro responsável pelo brotamento e desfolha sincrônicos e a segunda, pelo adiantamento da senescência foliar, principalmente na área do planalto.

A avaliação contínua dos incrementos em circunferência do tronco dos indivíduos de C. fissilis possibilitou caracterizar a periodicidade, o ritmo e a taxa de crescimento como resposta aos períodos de maior e/ou menor atividade cambial dos indivíduos (Figura 3). Foi observado, tanto no planalto como no litoral, que o crescimento em circunferência do

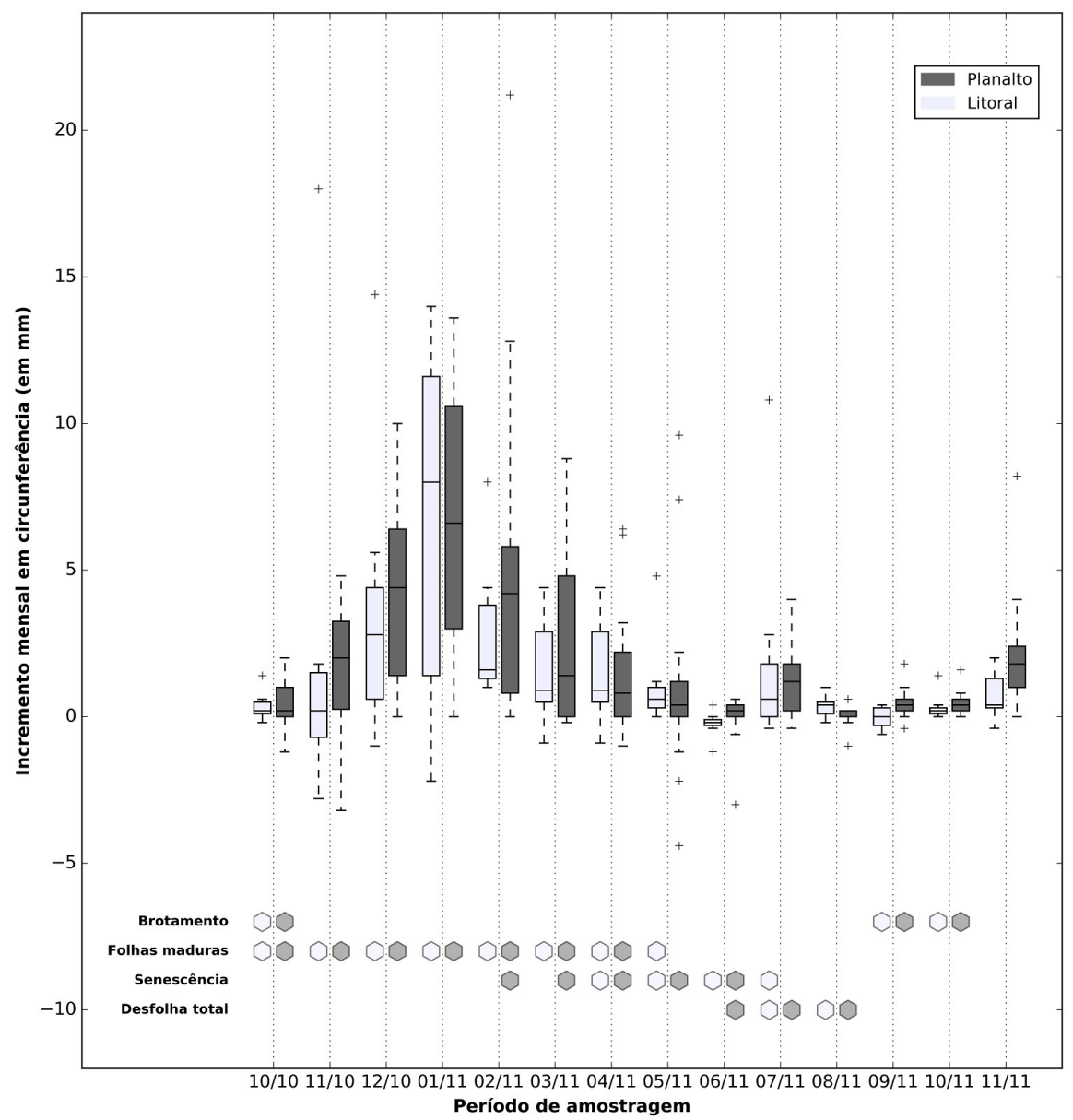

Figura 3. Dados mensais de fenologia vegetativa e taxas de crescimento em circunferência do tronco (Boxplot) de C. fissilis para ambas as áreas (litoral, $\mathrm{n}=7$; planalto, $\mathrm{n}=17$ ).

Figure 3. Monthly data of vegetative phenology and growth rates in girth increment (Boxplot) of C. fissilis for studied sites (coastal, $\mathrm{n}=7$; plateau, $\mathrm{n}=17$ ). 
tronco, em resposta à reativação do meristema cambial, inicia-se a partir do mês de outubro, após período de dormência (junho, julho e agosto). Observam-se taxas de incremento contínuas e graduais nos meses seguintes, sendo que as maiores taxas médias de incremento, para ambas as condições, foram observadas no mês de janeiro (verão). Esse período coincide com o de maior excedente hídrico no solo, altas temperaturas, maior comprimento do dia, além de as copas das árvores estarem completamente desenvolvidas. Após esse período, observa-se a diminuição gradual das taxas de incremento, com redução e/ou cessação no mês de junho, quando as árvores apresentam-se completamente sem folhas e/ou em fase adiantada de senescência.

A retomada do crescimento em circunferência do tronco foi observada a partir do mês de outubro. Isso se deve, em grande parte, a reativação do meristema cambial, em decorrência de hormônios produzidos por gemas foliares em desenvolvimento e folhas (Kozlowski \& Pallardy, 2008). A retomada da atividade cambial é dependente da fenologia que, por sua vez, parece estar fortemente relacionada com o fotoperíodo e a temperatura. Com a diminuição da produção hormonal, em consequência da senescência foliar, o câmbio diminui sua atividade e permanece inativo no período decíduo dos indivíduos. Vale ressaltar que as variações nas taxas de incremento dos indivíduos registradas refletem o crescimento de maneira indireta, pois registram também a reidratação do lenho e da casca, podendo, por isso, ser observadas variações na circunferência mesmo em períodos de redução e/ou de inatividade do câmbio vascular.

O padrão evidenciado sugere que, apesar de estar em um ambiente favorável ao crescimento - sem uma estação seca definida, os indivíduos apresentam uma natureza conservativa da espécie concernente a manutenção do crescimento sazonal (Costa et al., 2013). A formação anual do anel de crescimento nos dois ambientes ocorreu de maneira semelhante àquela observada por Marcati et al. (2006) para a espécie crescendo em floresta sazonal semidecidual. Ao final da estação de crescimento (junho) observou-se a formação de vasos de pequeno diâmetro tangencial e fina camada de parênquima axial marginal (Figura 4A). Observou-se, também, a formação de faixa de parênquima axial marginal (Figura 4B) isolada de elementos característicos do lenho inicial e/ou tardio, provavelmente não caracterizando um anel de crescimento anual. Na Figura 4C, referente ao mês de maio de 2011, observa-se as características anatômicas padrões do anel de crescimento de C. fissilis: vasos do lenho inicial caracterizados por maior diâmetro tangencial e embebidos em uma matriz de parênquima axial marginal, com diminuição progressiva do diâmetro tangencial desses durante o crescimento anual, finalizando o período de crescimento vegetativo com a deposição de uma bainha de parênquima axial marginal.

A presença de parênquima axial do tipo marginal demarcando o limite dos anéis anuais de crescimento foi previamente descrita para a espécie (Marcati et al., 2006; Lisi et al., 2008; Lobão, 2011). Essas células estão relacionadas com o armazenamento de carboidratos e o transporte de nutrientes, sendo, portanto, necessárias para a rápida reativação das divisões das células cambiais após a dormência cambial (Kozlowski et al., 1991; Dünisch et al., 2002). Assim como observado por Shimamoto et al. (2016) em outras espécies em área de Floresta Attântica no Sul do Brasil, a presença de parênquima axial marginal nessa espécie poderia ser justificada, de alguma forma, pela rápida retomada do crescimento observada nos meses com aumento de temperatura e de fotoperíodo.

A análise de fatorial de dados mistos extraiu três principais componentes de variação para ambos os locais de estudo. No litoral, as três componentes explicaram $83,13 \%$ da variabilidade do conjunto de dados, sendo que a contribuição foi de 46,95\%, 18,65\% e 17,53\%, para os componentes 1,2 e 3, respectivamente (Figura 5). Para o planalto também foram extraídas três componentes que explicaram $85,72 \%$ da variação, sendo que as contribuições foram de $51,65 \%, 18,8 \%$ e $15,26 \%$ para as componentes 1,2 e 3 , respectivamente (Figura 6). O padrão de correlações das componentes 1 e 2 foi o mesmo para ambas as localidades. A primeira componente apresentou correlação significativa com os incrementos mensais ( 0,82 litoral e 0,89 planalto); temperatura média (0,91 litoral e 0,91 planalto); comprimento do dia (0,75 litoral e 0,9 planalto); precipitação corrente ( 0,86 litoral e 0,82 planalto) e fenologia (0,56 litoral e 0,58 planalto), sendo que a categoria que mais contribuiu na correlação foi folhas maduras (ii). Nesse sentido, a primeira componente corresponde ao padrão de crescimento, uma vez que está relacionada ao período de maior taxa de incremento, melhores condições climáticas e ao momento em que as árvores apresentavam copas completamente 

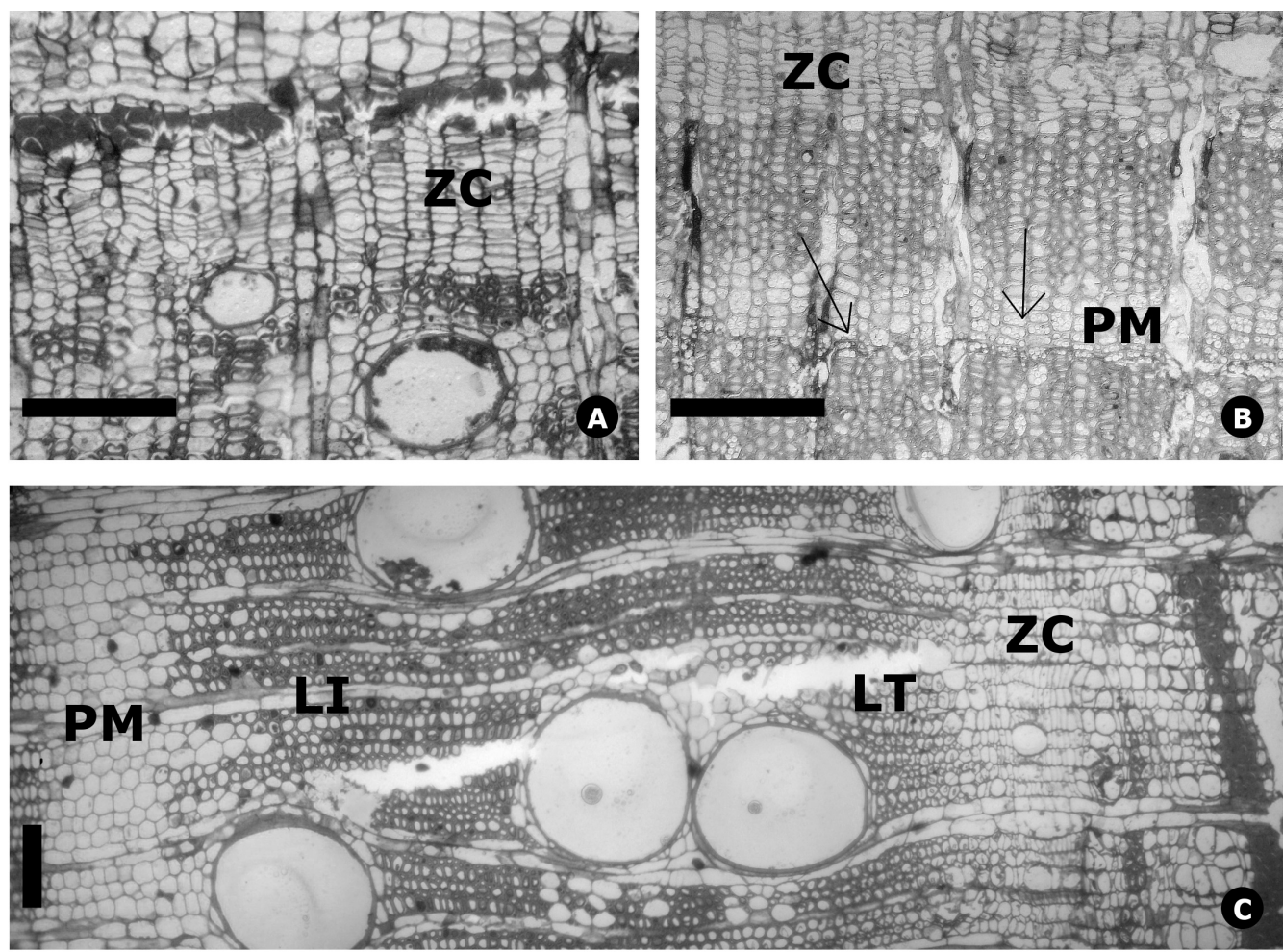

Figura 4. Secções transversais do câmbio vascular: (A) câmbio (ZC) inativo em junho de 2011; (B) reativação do câmbio vascular (ZC) em outubro de 2011, mostrando a presença de inúmeros grânulos de amido (setas) no interior das células do parênquima marginal (PM); (C) anel de crescimento característico de C. fissilis, com parênquima marginal (PM), vasos em arranjo padrão do tipo semiporoso, sendo os de maior diâmetro tangenciais no lenho inicial (LI) e os menores no lenho tardio (LT). Barras de $250 \mu \mathrm{m}$.

Figure 4. (A-B), vascular cambium cross-sections: (A) inactive cambium (ZC) in June 2010; (B) Reactivation of vascular cambium (ZC) in October 2011, showing starch grains (arrows) inside marginal parenchyma (PM); (C) characteristic C. fissilis growth ring with marginal parenchyma (PM), semi-ring-porous vessels, being the smaller vessels from early wood (LI) and big ones from late wood (LT). Bars with $250 \mu \mathrm{m}$.

desenvolvidas. Esse resultado já foi evidenciado em outros trabalhos, sendo observado que precipitação e temperatura são positivamente correlacionadas com a largura dos anéis de crescimento e com o incremento mensal da espécie (Andreacci et al., 2014; Lobão, 2011; Rauber, 2010).

A segunda componente foi significativamente correlacionada com a fenofase desfolha total (iv) (0,96 litoral e 0,90 planalto) e, para a área planalto, com a precipitação $(0,56)$. A correlação com a precipitação somente para a área planalto pode ser explicada pelo inverno atípico de 2011, que apresentou precipitação além do esperado para a época. Contudo, esse fato auxilia na interpretação da resposta fenológica da espécie, principalmente com relação à fenofase brotamento (i). Apesar do suplemento hídrico atípico, os indivíduos mantiveram o padrão fenológico de brotamento sincrônico com a área litoral, corroborando a hipótese anteriormente citada de que temperatura e comprimento do dia influenciam mais fortemente a fenologia da espécie, nas condições climáticas estudadas, do que a precipitação.

A terceira componente foi correlacionada significativamente com as fenofases brotamento (i) e senescência (iv) (0,97 litoral e 0,96 planalto), e não significativamente com crescimento corrente $(-0,262)$ e temperatura $(0,120)$. Essa componente corresponde aos períodos de menor crescimento dos indivíduos, sendo que durante o período senescência existe uma progressão gradual das taxas de incremento, enquanto que durante a fenofase brotamento o crescimento é retomado. 


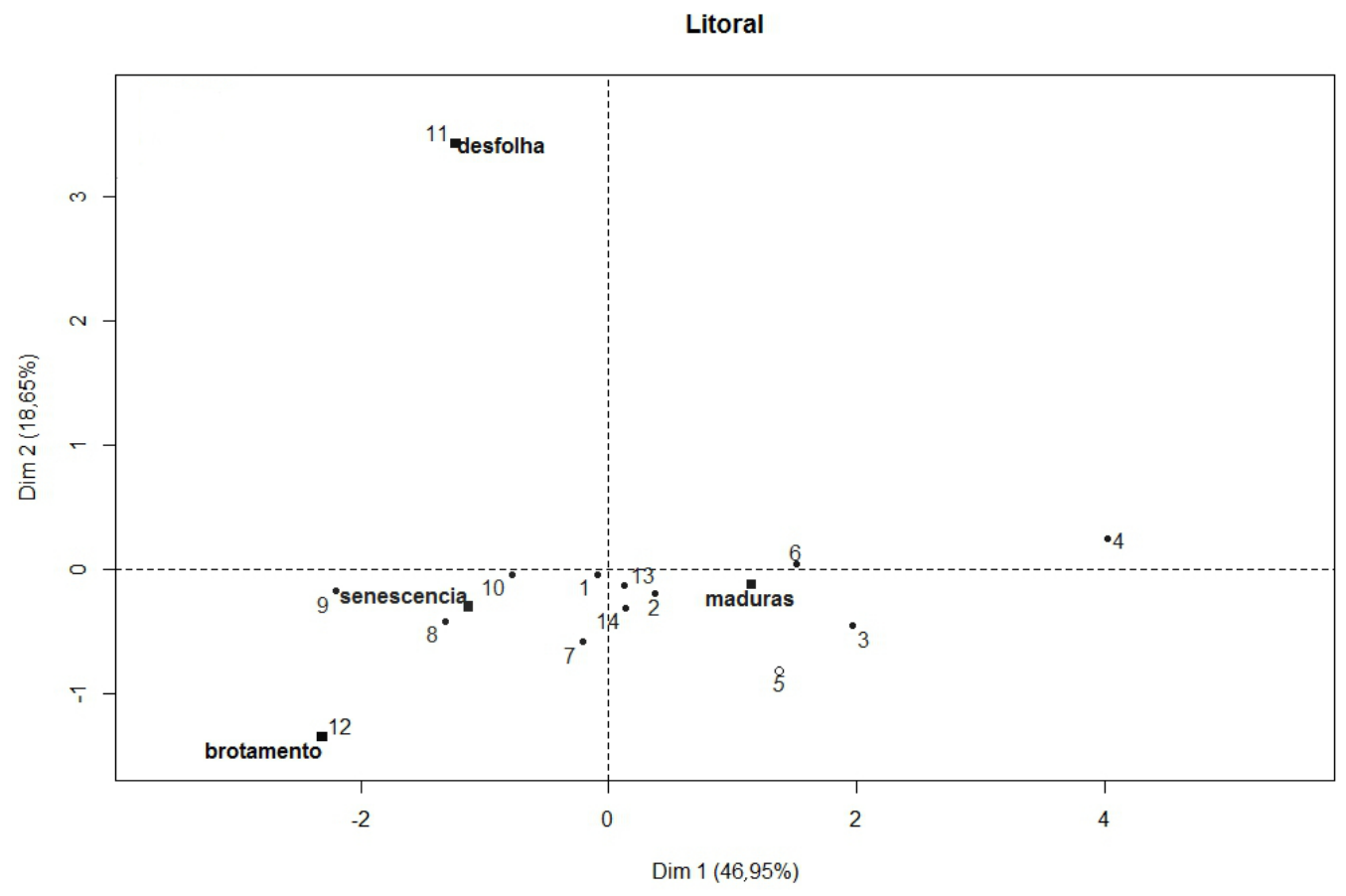

Figura 5. Análise fatorial de dados mistos para a área do litoral, eixos 1 (46,95\%) e 2 (18,68\%).

Figure 5. Factorial analysis of mixed data for coast site. Axes 1 (46.95\%) and 2 (18.68\%).

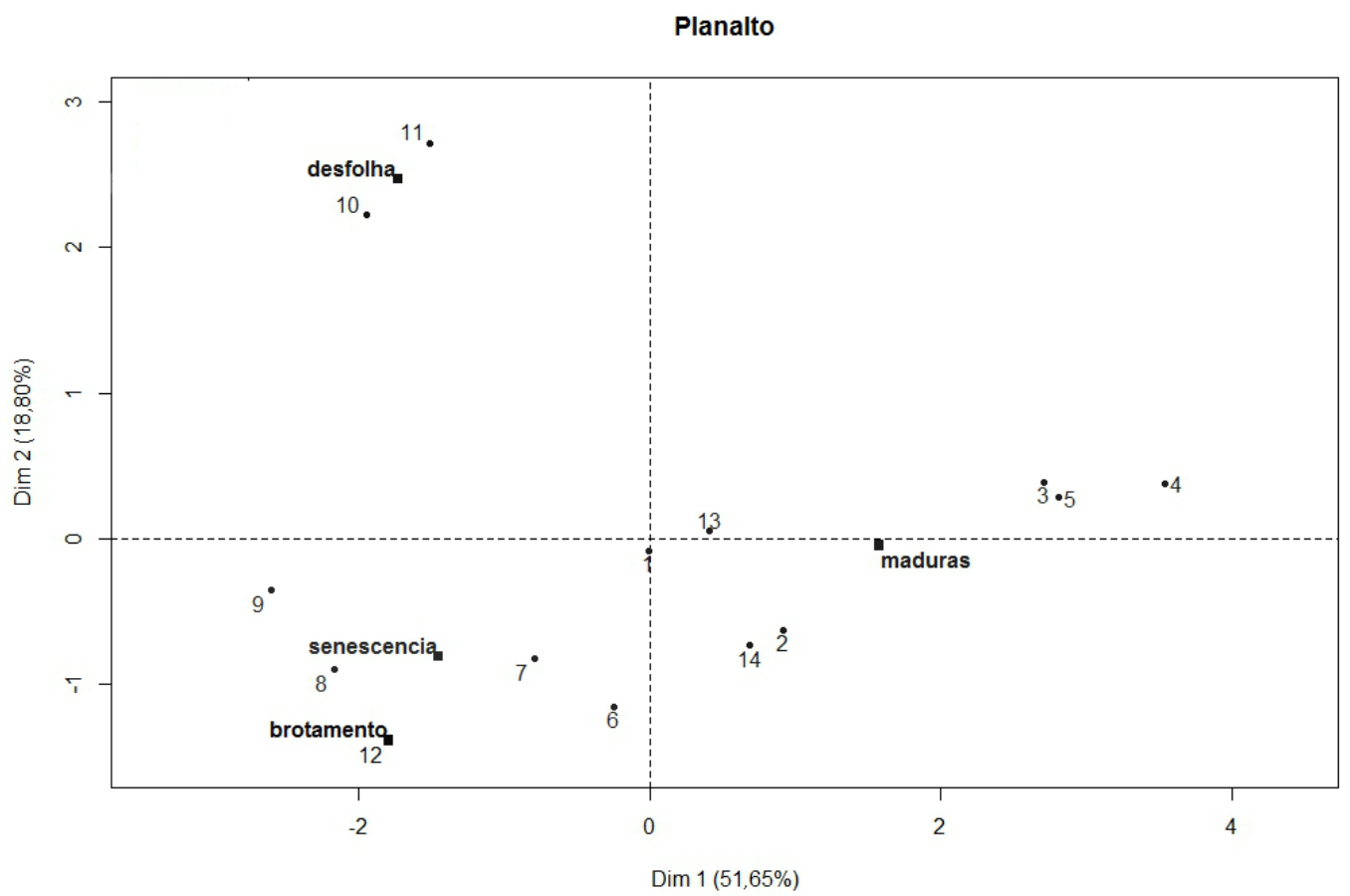

Figura 6. Análise fatorial de dados mistos para a área do planalto, eixos 1 (51,65\%) e 2 (18,80\%). Figure 6. Factorial analysis of mixed data for plateau site. Axes $1(51.65 \%)$ and $2(18.80 \%)$. 


\section{CONCLUSÕES}

O presente estudo demonstra a existência de sazonalidade fenológica e de incremento em circunferência do tronco de C. fissilis para as duas áreas de estudo. A fenologia dessa espécie, para as áreas estudadas, parece ser influenciada mais fortemente por fotoperíodo e temperatura do que pela precipitação. $\mathrm{O}$ crescimento em circunferência do tronco desses indivíduos é rítmico e sazonal, iniciando-se, mais intensamente, logo após a expansão total do limbo das folhas e sendo interrompido e/ou reduzido quando as folhas estão na fase de senescência adiantada. A espécie apresenta formação de anéis de crescimento anuais, sendo, no entanto, frequentemente observadas flutuações anatômicas da madeira intra-anéis, provavelmente de caráter não anual. Os resultados indicam que o crescimento em circunferência do tronco é mais controlado pela fenologia, pelas condições climáticas (e.g. temperatura e precipitação), além de por outros fatores relacionados, como comprimento do dia.

\section{STATUS DA SUBMISSÃO}

Recebido: 23 ago., 2016

Aceito: 28 ago., 2016

\section{AUTOR(ES) PARA CORRESPONDÊNCIA}

\section{Fernando Andreacci}

Laboratório de Planejamento e Manejo de Unidades de Conservação, Universidade do Vale do Itajaí - UNIVALI, Rua Uruguai, 458, Centro, CP 360, CEP 88302-901, Itajaí, SC, Brasil e-mail: fandreacci@gmail.com

\section{REFERÊNCIAS}

Alvim PT. Periodicidade do crescimento das árvores em climas tropicais. In: Anais do Congresso Nacional de Botânica; 1964; Porto Alegre. Porto Alegre: Universidade Federal do Rio Grande do Sul; 1964.

Andreacci F, Botosso PC, Galvão F. Sinais climáticos em anéis de crescimento de Cedrela fissilis em diferentes tipologias de florestas ombrófilas do sul do brasil. Floresta 2014; 44(2): 323-332. http://dx.doi.org/10.5380/rf.v44i2.27316.

Augspurger CK. Phenology, flowering synchrony, and fruit set of six neotropical shrubs. Biotropica 1983; 15(4): 257-267. http://dx.doi.org/10.2307/2387650.
Bencke CS, Morellato LPC. Comparação de dois métodos de avaliação da fenologia de plantas, interpretação e representação. Revista Brasileira de Biologia 2002; 25(3): 269-275.

Borchert R. Organismic and environmental controls of bud growth in tropical trees. In: Viémont JD, Crabbé J, editors. Dormancy in plants: from whole plant behavior to cellular control. Wallingford: CABI; 2000.

Botosso PC, Tomazello-Filho M. Aplicação de faixas dendrométricas na dendrocronologia: avaliação da taxa e do ritmo de crescimento do tronco de árvores tropicais e subtropicais. In: Maia NB, Martos HL, Barella W, ediores. Indicadores ambientais: conceitos e aplicações. São Paulo: EDUC; 2001.

Callado CH, Silva SJ No, Scarano FR, Barros C, Costa CG. Anatomical features of growth rings in floodprone trees of Atlantic rain Forest in Rio de Janeiro, Brazil. IAWA Journal 2001; 22(1): 29-42. http://dx.doi. org/10.1163/22941932-90000266.

Cardoso FCG, Marques R, Botosso PC, Marques MCM. Stem growth and phenology of two tropical trees in contrasting soil conditions. Plant and Soil 2012; 354(1-2): 269-281. http://dx.doi.org/10.1007/s11104-011-1063-9.

Costa MS, Vasconcellos TJ, Barros CF, Callado CH. Does growth rhythm of a widespread species change in distinct growth sites? IAWA Journal 2013; 34(4): 498-509. http:// dx.doi.org/10.1163/22941932-00000040.

Dünisch O, Bauch J, Gasparotto L. Formation of increment zones and intraannual growth dynamics in the xylem of Swietenia macrophylla, Carapa guianensis, and Cedrela odorata (Meliaceae). IAWA Journal 2002; 23(2): 101-119. http://dx.doi.org/10.1163/22941932-90000292.

Fahn A, Burley J, Longman A, Mariaux A, Tomlinson P. Possible contributions of wood anatomy to the determination of the age of tropical trees. In: Bormann FH, Berlyn G, editors. Age and growth rate of tropical trees: new directions for research. New Haven: Yale University; 1981.

Ferraz DK, Artes R, Mantovani W, Magalhães LM. Fenologia de árvores em fragmento de mata em São Paulo, SP. Revista Brasileira de Biologia 1999; 59(2): 305-317. http://dx.doi. org/10.1590/S0034-71081999000200013.

Ferretti AR, Britez RM. Ecological restoration carbon sequestration and biodiversity conservation: the experience of the Society for Wildlife Research and Environmental Education (SPVS) in the Atlantic Rain Forest of Southern Brazil. Journal for Nature Conservation 2006; 14(3-4): 249-259. http://dx.doi.org/10.1016/j.jnc.2006.04.006.

Hilty SL. Flowering and fruiting periodicity in a premontane rain forest in Pacific Colombia. Biotropica 1980; 12(4): 292-306. http://dx.doi.org/10.2307/2387701.

Jacoby GC. Overview of tree-ring analysis in tropical regions. IAWA Bulletin 1989; 10(2): 99-108. http://dx.doi. org/10.1163/22941932-90000478. 
Kozlowski TT, Kramer PJ, Pallardy SG. The physiological ecology of woody plants. San Diego: Academic Press; 1991.

Kozlowski TT, Pallardy SG. Physiology of woody plants. Burlington: Academic Press; 2008.

Lisi CS, Tomazello-Filho M, Botosso PC, Roig FA, Maria VRB, Ferreira-Fedele L et al. Tree-ring formation, radial increment periodicity and phenology of tree species from a Seasonal Semi-Decidous Forest in Southeast Brazil. IAWA Journal 2008; 29(2): 189-207. http://dx.doi. org/10.1163/22941932-90000179.

Lobão MS. Dendrocronologia, fenologia, atividade cambiale qualidade do lenho de árvores de Cedrela odorata L., Cedrela fissilis Vell. e Schizolobium parahyba var. amazonicum Hub. ex Ducke, no estado do Acre, Brasil [tese]. Piracicaba: Escola Superior de Agricultura "Luiz de Queiroz", Universidade de São Paulo; 2011.

Marcati CR, Angyalossy V, Evert RF. Seasonal variation in wood formation of Cedrela fissilis (Meliaceae). IAWA Journal 2006; 27(2): 199-211. http://dx.doi.org/10.1163/2294193290000149 .

Marques MCM, Roper JJ, Salvalaggio APB. Phenological patterns among plant life forms in a subtropical forest in Southern Brazil. Plant Ecology 2004; 173(2): 203-213. http://dx.doi.org/10.1023/B:VEGE.0000029325.85031.90.

Mittermeier RA, Gil PR, Hoffman M, Pilgrim J, Brooks T, Mittermeier CG et al. Hotspots revisited: earth's biologically richest and most endangered terrestrial ecoregions. Washington, DC: Conservation International; 2005.

Morellato LPC, Rodrigues RR, Leitão-Filho HF, Joly CA. Estudo fenológico comparativo de espécies arbóreas de floresta de altitude e floresta mesófila semidecídua na Serra do Japi, Jundiaí, SP. Revista Brasileira de Botanica. Brazilian Journal of Botany 1989; 12(1): 85-98.

Morellato LPC, Talora DC, Takahasi A, Bencke CC, Romera EC, Zipparro VB. Phenology of Atlantic Rain Forest trees: a comparative study. Biotropica 2000; 32(4): 811-823. http://dx.doi.org/10.1111/j.1744-7429.2000.tb00620.x.

Muellner AN, Pennington TD, Koecke AV, Renner SS. Biogeography of Cedrela (Meliaceae, Sapindales) in Central and South America. American Journal of Botany 2010; 97(3): 511-518. PMid:21622412. http://dx.doi. org/10.3732/ajb.0900229.

O'Brien JJ, Oberbauer SF, Clark DB, Clark DA. Phenology and stem diameter increment seasonality in a Costa Rican wet tropical forest. Biotropica 2008; 40(2): 151-159. http:// dx.doi.org/10.1111/j.1744-7429.2007.00354.x.

O'Brien TP, Feder N, McCully ME. Polychromatic staining of plant cell walls by Toluidine Blue O. Protoplasma 1964; 59(2): 368-373. http://dx.doi.org/10.1007/BF01248568.
Opler PA, Frankie GW, Baker HG. Rainfall as a factor in the release, timing, and synchronization of anthesis by tropical trees and shrubs. Journal of Biogeography 1976; 3(3): 231-236. http://dx.doi.org/10.2307/3038013.

Pagès J. Multiple factor analysis by example using. London: Chapman and Hall; 2014.

Pinheiro AL, Maragon LC, Paiva GLRMP. Características fenológicas do Cedro (Cedrela fissilis Vell.) em Viçosa, Minas Gerais. Boletim de Pesquisa Florestal 1990; 21(1): 21-26.

Rauber CR. Dendroecologia de Cedrela fissilis Vell. (Meliaceae) em um ecótono de Florestas Subtropicais Montanas no Brasil [dissertação]. Porto Alegre: Universidade Federal do Rio Grande do Sul; 2010.

Reich PB, Borchert R. Water stress and tree phenology in a tropical dry forest in the lowlands of Costa Rica. Journal of Ecology 1984; 72(1): 61-74. http://dx.doi. org/10.2307/2260006.

Rivera G, Borchert R. Induction of flowering in tropical trees by a 30-min reduction in photoperiod: evidence from field observations and herbarium specimens. Tree Physiology 2001; 21(4): 201-212. PMid:11276414. http:// dx.doi.org/10.1093/treephys/21.4.201.

Rizzini CT. Tratado de fitogeografia do Brasil. São Paulo: EDUSP; 1979.

Roig FA. Dendrocronología en los bosques del neotrópico: revisión y prospección futura. In: Roig FA, editor. Dendrocronología en América Latina. Mendoza: EIUNC; 2000.

Shimamoto CY, Botosso PC, Amano E, Marques MCM. Stem growth rhythms in trees of a tropical rainforest in Southern Brazil. Trees - Structure and Function 2016; 30: 99-111.

Sistema Meteorológico do Paraná - SIMEPAR. Dados climáticos diários dos municípios de Antonina e Curitiba. Curitiba: SIMEPAR; 2016.

Van Schaik CP, Terborgh JW, Wright SJ. The phenology of Tropical Forests: adaptive significance and consequences for primary consumers. Annual Review of Ecology and Systematics 1993; 24(1): 353-377. http://dx.doi.org/10.1146/ annurev.es.24.110193.002033.

Varejão-Silva MA. Meteorologia e Climatologia. Brasília, DF: Gráfica e Editora Stilo, 2000.

Walter H, Lieth H. Climate diagram world atlas. Jena: Gustav Fischer; 1967.

Wright SJ, van Schaik CP. Light and the phenology of Tropical Trees. American Naturalist 1994; 143(1): 192199. http://dx.doi.org/10.1086/285600.

Wright SJ. Seasonal drought and the phenology of understory shrubs in a Tropical Moist Forest. Ecology 1991; 72(5): 1643-1657. http://dx.doi.org/10.2307/1940964. 